\title{
Attitude towards Information and Communication Technology among Rural and Urban Primary and Secondary School Teachers of Punjab
}

\author{
Parminder Kaur ${ }^{1}$, Dr. Sunita Arya ${ }^{2}$ \\ 1Department of Education, Desh Bhagat University, Mandi Gobindgarh, Punjab, India \\ ${ }^{2}$ Principal, Higher Education Kingra, Malout, Punjab, India
}

\begin{abstract}
How to cite this paper: Parminder Kaur | Dr. Sunita Arya "Attitude towards Information and Communication Technology among Rural and Urban Primary and Secondary School Teachers of Punjab" Published in International Journal of Trend in Scientific Research and Development (ijtsrd), ISSN: 24566470, Volume-3 | Issue-3 , April 2019, pp.859-864, URL: https://www.ijtsrd.c om/papers/ijtsrd23 131.pdf

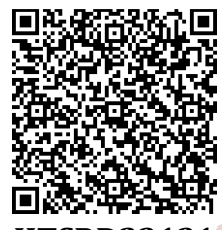

IITSRD23131
\end{abstract}

Copyright (C) 2019 by author(s) and International Journal of Trend in Scientific Research and Development Journal. This is an Open Access article distributed under the terms of the Creative Commons

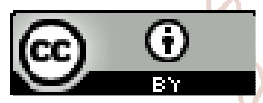
Attribution License (CC BY 4.0) (http://creativecommons.org/licenses/ by $/ 4.0$ )

Information and Communication Technology is the buzzword today everywhere as the world has entered into an information and communication age . Development in information and communication technology is going to open up new and cost -effective approaches for expanding the reach of education to children, youth as well as to those who need continuing education to meet the demands of explosion of information, fast-changing nature of occupations and life -long education. The consensus of opinion among social scientists and business planners is that information and communication technology is a growing area in the foreseeable future and can create vast opportunities in almost all areas of life.

According to Adeya (2002) ICTs are embedded in networks and services that affect the local and global accumulation and flows of public and private knowledge. Moreover, Adeya mentions about a more simplified definition describing ICT as an 'electronic means of capturing, processing, storing and disseminating information '.In broader sense ,the term, Information and Communication Technologies (ICT) refers to forms of technologies that are used to create, store, share or transmit and exchange information. This broad definition of ICT includes such technologies as radio, television,video, DVD, telephone both fixed line and mobile phones, satellite systems ,computer and network hardware and software; as well as the equipment and services associated with these technologies, such as videoconferencing and electronic mail.( UNESCO, 2002)

\section{ATTITUDE TOWARDS ICT}

An effective educational environment is also characterized by a positive school climate where the teachers and students feel good about teaching and learning and cooperate to foster a caring attitude. Attitude has great importance in learning and teaching. It is one of the important objectives of teaching and learning to develop attitudes in the process of school subjects. A review of the psychological literature reveals diverse definitions of attitudes. According to International Encyclopedia of Education (1991), Attitude is a term which has been used to describe in general way the reaction of a subject upon any impression received from his environment. Used in this fashion it is sufficiently comprehensive to include feeling, attention and other similar general phases of mental experience. It refers also to bodily activities when these are directed towards given 
object and thus serves the useful purpose of associating in discussion mental states with the bodily reaction which condition or by which they are themselves conditioned.

\section{REVIEW OF RELATED LITERATURE ON ATTITUDE TOWARDS ICT}

Das (2003) examined a study entitled on 'Computer Education in the Secondary Schools of Assam'. The objectives of the study were: (i) To assess the attitude of students and teachers towards computer education, infrastructural facilities in the schools and gender disparities in computer science, if any, in both Government and private secondary schools of Assam. (ii) To assess the knowledge of the students in computer science, experiences with computers and also the teachers' educational background and their experiences with computer and (iii) To find out the differences, if any, between the Assamese medium and English medium students of both the Government and private schools in computer education. The Findings of the study highlighted that students had a positive attitude and outlook towards computer education received in their respective schools. Some students suggested a revamping of the traditional modes of teaching by introducing computers in teaching which they thought will make their education more exciting and interesting. Teachers were confident about their knowledge of the subject; they were not found to be devoid of anxiety. The English medium students were found to display higher level of confidence, a sense of competence in their approach to and use of computers than the Assamese medium students. In spite of funding and all other infrastructural facilities provided by the North Eastern council in a collaborative venture with the Board of Secondary Education, Assam, nothing fruitful or lasting evolved from the course of computer education imparted to the students of government schools. Girls were found to have a positive attitude towards computer as being more user friendly and expressed less anxiety about the use of computers.

Albirini (2004) conducted a study on the attitudes of EFL teachers in Syrian high schools toward ICT in education and to explore the relationship of teachers' attitudes with a selected set of variables. Teachers' attitudes were examined from two related theoretical frameworks : Rogers's (1995) Diffusion of Innovations and Ajzen and Fishbein's (1980) Model of Reasoned Action. A questionnaire was developed and distributed to 326 sample teachers selected randomly from the population. The survey stage was followed by indepth phone interviews with a purposeful sample of 15 teachers. Results from both quantitative and qualitative data indicated that the participants had positive attitudes toward ICT in education. While the participants had somewhat positive perceptions of the attributes of computers, they were relatively neutral about the cultural relevance of ICT to Syrian society and schools, the teachers also reported low levels of computer competence, access, and training. Significant positive correlations existed between teachers' attitudes toward ICT and five independent variables, including computer attributes, cultural perceptions, computer competence, computer access and computer training. Multiple regression analysis indicated that only the first three of the above independent variables had a significant predictive value of computer attitudes toward ICT . The results indicated that $0.58 \%$ of the variance in computer attitude was explained by the independent variables included in this study.
In a study 'Teacher's attitude towards computer use: Implications for emerging technology implementation in educational institutions' Mehra (2007) determined the attitudes of school teachers in Chandigarh towards use of computer technology for instructional purpose. The objectives of the study were to study the attitudes of high school teachers towards computer use and to study the perceptions of school teachers with respect to computer attributes, level of computer competence and their access to computers. The findings of the study revealed that the teachers possessed fairly positive attitude towards computer use but majority of the teachers needed to be provided with training for using computers in instructional settings.

Cavas (2009) investigated the Turkish primary science teachers' "attitudes toward ICT in education and explored the relationship between teachers' attitudes and factors which were related to teachers' personal characteristics (gender, age, computer ownership at home, and computer experience). In order to collect data, an instrument (STATICTE) was developed by researchers and administered to 1071 science teachers almost uniformly distributed in 7 geographic regions of Turkey. In data analyses, descriptive statistics were used to describe and summarize the properties of the mass of data collected from the respondents. The results indicated that Turkish science teachers have positive attitudes toward ICT and although teachers' attitudes toward ICT did not differ regarding gender, it differed regarding age, computer ownership at home and computer experience.

\section{NEED OF THE STUDY}

The world is changing fast due to the technological developments. Application of technologies is seen in almost all aspects of education. The wider changes taking place in the society are providing a context for instructional development. Over the years there is a shift from oral to written, formal to non-formal, teacher centered to student centered and rigid to flexible forms of instruction. The information age requires a higher level of skill and knowledge of all individuals. Teachers' professional knowledge, skill and capabilities are enhanced by ICT as their subject knowledge is expending. ICT enables teachers in planning and preparing them for more efficient teaching. Today's teachers find themselves wandering in a situation, where they have to make use of computers to update their knowledge and deliver lessons through the computer and on the other side of the picture, they face certain stress full symptoms while dealing with the computer in the classroom. Most teachers agree that computers are very useful tool but few of them use computers extensively in the classroom. Teachers with anxiety either avoid teaching with computers or if they do not teach with them pass their anxiety and negative attitude to their students. Researches indicate low adoption of computer technology when institutions simply purchase hardware and software programmes for their users, without positive attitudes and computer self efficacy faculty members are less likely to increase their use of technology or consider the integration of technology in their instructional activity (Dunlop, 2005).

This kind of situation is also prevalent in the Indian classroom where teachers have anxiety or phobia to use technology, this results in a sense of low ict self efficacy negative attitudes to use ict in their classroom. So there is need to investigate Attitude towards Information and 
International Journal of Trend in Scientific Research and Development (IJTSRD) @ www.ijtsrd.com eISSN: 2456-6470

Communication Technology (ICT) among rural and urban primary and secondary school teachers of Punjab.

\section{OBJECTIVES OF THE STUDY}

The following are the objectives of the study:

$>$ To assess attitude towards ict of rural and urban teachers

$>$ To assess attitude towards ICT of primary and secondary school teachers of Punjab

$>$ To assess attitude towards ICT of school teachers with different academic streams.

\section{HYPOTHESES OF THE STUDY}

The following hypothesis have been framed:

1. There is no significant difference in primary and secondary school teachers with respect to dimensions of attitude towards ICT.

2. There is no significant difference in rural and urban school teachers with respect to dimensions of attitude towards ICT.

3. There is no significant difference in dimensions of attitude towards ICT. Of school teachers on the basis of academic streams.

\section{DELIMITATION OF THE STUDY}

1. The study is delimited to only 400 teachers.

2. The study is delimited to only rural and urban teachers.

\section{METHOD}

A sample of 400 teachers were selected randomly; 200 rural teachers ( 100 primary and 100 secondary) and 200 urban teachers (again 100 primary and 100 secondary).for study, descriptive and survey method has been used .

\section{TOOL}

Keeping in view the nature of the present study the investigator used attitude towards ICT given by Sanada Saini (2015)

\section{RESULTS AND DISCUSSION}

The attitude towards ict of school teachers were measured with the help of Sunada saini's attitude towards ict scale which measures three parts i.e 1) Affective Attitude 2) Perceived Usefulness 3) Perceived Control component.

1 Analysis of attitude towards ICT of primary and secondary schools

Table 1.1: Descriptive statistics and Independent sample t-test of affective attitude towards ICT with respect to

\begin{tabular}{|c|c|c|c|c|c|c|c|c|}
\hline Variable & Group & & $\mathbf{N}$ & Mean & S.D. & $\mathrm{T}$ & $D f$ & $P$ \\
\hline \multirow{2}{*}{ Affective attitude towards ICT } & \multirow{2}{*}{ Level of school } & Primary & 200 & 3.3525 & .50625 & \multirow{2}{*}{-2.871} & \multirow{2}{*}{798} & \multirow{2}{*}{.004} \\
\hline & & Secondary & 200 & 3.4585 & .53759 & & & \\
\hline
\end{tabular}

Note: $\mathrm{N}=$ Sample size; S.D. = Standard deviation; $d f=$ degree of freedom; $p=$ Significance value; $\mathrm{t}=$ Students's $\mathrm{t}$ - statistics value

\section{Interpretation}

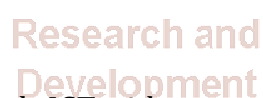

Table(1.1) shows the average affective attitude towards ICT with respect to the primary and secondary school teachers. As can be seen from the table that average score of affective attitude towards ICT is low among primary school teachers as compared to secondary school teachers. This has been further tested for statistical significance with the help of independent sample t-test. As evident $p$ value is less than assumed level of significance (0.05). Therefore, there is difference in affective attitude towards ICT of teachers working in primary and secondary schools of Punjab.

Table 1.2: Descriptive statistics and Independent sample t-test of perceived usefulness of ICT respect to level of school

\begin{tabular}{|c|c|c|c|c|c|c|c|c|}
\hline Variable & Group & & $\mathbf{N}$ & Mean & S.D. & $\mathrm{T}$ & $D f$ & $P$ \\
\hline \multirow{2}{*}{ Perceived usefulness of ICT } & \multirow{2}{*}{ Level of school } & Primary & 200 & 3.9487 & .45515 & \multirow{2}{*}{-6.675} & \multirow{2}{*}{798} & \multirow{2}{*}{.000} \\
\hline & & Secondary & 200 & 4.1565 & .42510 & & & \\
\hline
\end{tabular}

Note: $\mathrm{N}=$ Sample size; S.D. = Standard deviation; $d f=$ degree of freedom; $p=$ Significance value; $\mathrm{t}=$ Students's $\mathrm{t}$ - statistics value

\section{Interpretation}

The table(1.2) represents the average perceived usefulness of ICT with respect to the primary and secondary school teachers. It is evident from the table that average score of perceived usefulness of ICT is low for primary school teachers than secondary school teachers. This has been tested for statistical significance with the help of independent sample t-test. As it can be seen that $p$ value is lower than assumed level of significance (0.05). Therefore, there is difference in perceived usefulness of ICT of teachers working in primary and secondary schools of Punjab.

Table 1.3: Descriptive statistics and Independent sample t-test of perceived control component of ICT with respect to level of school

\begin{tabular}{|c|c|c|c|c|c|c|c|c|}
\hline Variable & Group & & N & Mean & S.D. & $\mathrm{T}$ & $D f$ & $P$ \\
\hline \multirow{2}{*}{ Perceived control component of ICT } & \multirow{2}{*}{ Level of school } & Primary & 200 & 3.3731 & .32985 & \multirow{2}{*}{-3.583} & \multirow{2}{*}{798} & \multirow{2}{*}{.000} \\
\hline & & Secondary & 200 & 3.4625 & .37451 & & & \\
\hline
\end{tabular}

Note: $\mathrm{N}=$ Sample size; S.D. = Standard deviation; $d f=$ degree of freedom; $p=$ Significance value; $\mathrm{t}=$ Students's $\mathrm{t}$ - statistics value 


\section{Interpretation}

Table (1.3) shows the average perceived control component of ICT with respect to the primary and secondary school teachers. As can be seen from the table that average score of perceived control component of ICT is higher for secondary school teachers in comparison to primary school teachers. This difference in mean values has been tested for statistical significance with the help of independent sample t-test. As evident $p$ value is less than assumed level of significance (0.05). Therefore, there is significant difference in perceived control component of ICT among teachers working in primary and secondary schools of Punjab.

Hence, null hypothesis $\mathrm{H} 1$ that there is no significant difference in primary and secondary school teachers is rejected with respect to affective attitude towards ICT, perceived usefulness of ICT and perceived control component of ICT

\section{Analysis of attitude towards ICT scores of rural and urban schools}

Table 2.1: Descriptive statistics and Independent sample t-test of affective attitude towards ICT with respect to locality of school

\begin{tabular}{|c|c|c|c|c|c|c|c|c|}
\hline Variable & Group & & N & Mean & S.D. & T & Df & $P$ \\
\hline \multirow{2}{*}{ Affective attitude towards ICT } & \multirow{2}{*}{ Locality of school } & Rural & 200 & 3.4665 & .50410 & \multirow{2}{*}{3.310} & \multirow{2}{*}{798} & \multirow{2}{*}{.001} \\
\cline { 3 - 7 } & & Urban & 200 & 3.3445 & .53791 & & \\
\hline
\end{tabular}

Note: $\mathrm{N}=$ Sample size; S.D. = Standard deviation; $d f=$ degree of freedom; $p=$ Significance value; $\mathrm{t}=$ Students's $\mathrm{t}$ - statistics value

\section{Interpretation}

The table(2.1) represents the average affective attitude towards ICT with respect to the teachers from rural and urban school. It is evident from the table that average score of affective attitude towards ICT is higher for rural school teachers than urban school teachers. This has been tested for statistical significance with the help of independent sample t-test. As it can be seen that $p$ value is lower than assumed level of significance (0.05). Therefore, there is significant difference in affective attitude towards ICT of teachers working in rural and urban schools of Punjab.

Table 2.2: Descriptive statistics and Independent sample t-test of perceived usefulness of ICT respect to locality of

\begin{tabular}{|c|c|c|c|c|c|c|c|c|}
\hline Variable & Groun & & $\mathbf{N}$ & Mean & S.D. & t & $D f$ & D \\
\hline \multirow{2}{*}{ Perceived usefulness of ICT } & \multirow{2}{*}{ Locality of school } & Rural & 200 & 4.1022 & .46190 & \multirow{2}{*}{3.121} & \multirow{2}{*}{798} & \multirow{2}{*}{.002} \\
\hline & & Urban & 200 & 4.0030 & .43730 & & & \\
\hline
\end{tabular}

Note: $\mathrm{N}=$ Sample size; S.D. = Standard deviation; $d f=$ degree of freedom; $p=$ Significance value; $\mathrm{t}=$ Students's $\mathrm{t}$ - statistics value

\section{Interpretation}

Table(2.2) shows the average perceived usefulness component of ICT with respect to the rural and urban school teachers. As can be seen from the table that average score of perceived usefulness component of ICT is higher for rural school teachers in comparison to urban school teachers. This difference in mean values has been tested for statistical significance with the help of independent sample t-test. As evident $p$ value is less than assumed level of significance (0.05). Therefore, there is significant difference in perceived usefulness component of ICT among teachers working in rural and urban schools of Punjab.

Table 2.3: Descriptive statistics and Independent sample t-test of perceived control component of ICT with respect to locality of school

\begin{tabular}{|c|c|c|c|c|c|c|c|c|}
\hline Variable & Group & & $\mathbf{N}$ & Mean & S.D. & $\mathbf{t}$ & $D f$ & $P$ \\
\hline \multirow{2}{*}{ Perceived control component of ICT } & \multirow{2}{*}{ Locality of school } & Rural & 200 & 3.4746 & .34290 & \multirow{2}{*}{4.571} & \multirow{2}{*}{798} & \multirow{2}{*}{.000} \\
\hline & & Urban & 200 & 3.3611 & .35920 & & & \\
\hline
\end{tabular}

Note: $\mathrm{N}=$ Sample size; S.D. = Standard deviation; $d f=$ degree of freedom; $p=$ Significance value; $\mathrm{t}=$ Students's $\mathrm{t}$ - statistics value

\section{Interpretation}

The table(2.3) represents the average perceived control component of ICT with respect to the rural and urban school teachers. It is evident from the table that average score of perceived control component of ICT is higher for rural school teachers than urban school teachers. This has been tested for statistical significance with the help of independent sample t-test. As it can be seen that $p$ value is lower than assumed level of significance (0.05). Therefore, there is significant difference in perceived control component of ICT of teachers working in rural and urban schools of Punjab.

Hence, null hypothesis $\mathrm{H} 2$ that there is no significant difference in rural and urban school teachers is rejected with respect to affective attitude towards ICT, perceived usefulness of ICT and perceived control component of ICT

3 Analysis of attitude towards ICT scores according to academic streams

Table 3.1: Descriptive statistics and Independent sample t-test of affective attitude towards ICT with respect to

\begin{tabular}{|c|c|c|c|c|c|c|c|c|}
\hline Variable & Group & & $\mathbf{N}$ & Mean & S.D. & $\mathrm{T}$ & $D f$ & $P$ \\
\hline \multirow{2}{*}{$\begin{array}{l}\text { Affective attitude } \\
\text { towards ICT }\end{array}$} & \multirow{2}{*}{$\begin{array}{l}\text { Academic } \\
\text { streams }\end{array}$} & Science / Mathematics & 217 & 3.3856 & .52126 & \multirow[b]{2}{*}{1.106} & \multirow[b]{2}{*}{797} & \multirow[b]{2}{*}{.269} \\
\hline & & $\begin{array}{c}\text { Social } \\
\text { Sciences/Language }\end{array}$ & 182 & 3.4267 & .52847 & & & \\
\hline
\end{tabular}

Note: $\mathrm{N}=$ Sample size; S.D. = Standard deviation; $d f=$ degree of freedom; $p=$ Significance value; $\mathrm{t}=$ Students's $\mathrm{t}$ - statistics value 


\section{Interpretation}

The table (3.1) depicts affective attitude towards ICT of school teachers on the basis of academic streams. It can be seen from the table that average score of affective attitude towards ICT is lower for science and mathematics teachers as compared to the social science teachers. Independent sample t-test as performed to test its statistical significance. As it is depicted from the table that $p$ value is greater than assumed level of significance (0.05). Therefore, there is no significant difference in affective attitude towards ICT in school teachers on the basis of academic streams of Punjab.

Hence, null hypothesis $\mathrm{H} 3$ i.e. there is no significant difference in affective attitude towards ICT of school teachers on the basis of academic streams is accepted.

Table 3.2: Descriptive statistics and Independent sample t-test of perceived usefulness of ICT respect to academic

\begin{tabular}{|c|c|c|c|c|c|c|c|c|}
\hline Variable & Group & & $\mathbf{N}$ & Mean & S.D. & $\mathbf{T}$ & $d f$ & $P$ \\
\hline \multirow{2}{*}{$\begin{array}{l}\text { P erceived usefulness of } \\
\text { ICT }\end{array}$} & \multirow{2}{*}{$\begin{array}{l}\text { Academic } \\
\text { streams }\end{array}$} & Science / Mathematics & 217 & 4.0516 & .44030 & \multirow{2}{*}{.072} & \multirow[b]{2}{*}{797} & \multirow[b]{2}{*}{.942} \\
\hline & & $\begin{array}{c}\text { Social } \\
\text { Sciences/Language }\end{array}$ & 182 & 4.0539 & .46601 & & & \\
\hline
\end{tabular}

Note: $\mathrm{N}=$ Sample size; S.D. = Standard deviation; $d f=$ degree of freedom; $p=$ Significance value; $\mathrm{t}=$ Students' $\mathrm{t}$ - statistics value

\section{Interpretation}

The table (3.2) depicts perceived usefulness of ICT of school teachers on the basis of academic streams. It can be seen from the table that average score of perceived usefulness of ICT is similar for science and mathematics teachers and social science teachers. Independent sample t-test as performed to test its statistical significance. As it is depicted from the table that $p$ value is greater than assumed level of significance (0.05). Therefore, there is no significant difference in perceived usefulness of ICT in school teachers on the basis of academic streams of Punjab.

Hence, null hypothesis $\mathrm{H} 3$ i.e. there is no significant difference in perceived usefulness of ICT on the basis of academic streams is accepted.

Table 3.3: Descriptive statistics and Independent sample t-test of perceived control component of ICT with respect

\begin{tabular}{|c|c|c|c|c|c|c|c|c|}
\hline Variable & Group & & $\mathbf{N}$ & Mean & S.D. & $\mathbf{T}$ & $d f$ & $P$ \\
\hline \multirow{2}{*}{$\begin{array}{c}\text { Perceived control component } \\
\text { of ICT }\end{array}$} & \multirow{2}{*}{$\begin{array}{l}\text { Academic } \\
\text { streams }\end{array}$} & Science / Mathematics & 217 & 3.4130 & .35141 & \multirow{2}{*}{$\begin{array}{c}- \\
.397\end{array}$} & \multirow[b]{2}{*}{797} & \multirow[b]{2}{*}{.691} \\
\hline & & $\begin{array}{l}\text { DevelSocialnt } \\
\text { Sciences/Language }\end{array}$ & 182 & 3.4230 & .36074 & & & \\
\hline
\end{tabular}

Note: $\mathrm{N}=$ Sample size; S.D. = Standard deviation; $d f=$ degree of freedom; $p=$ Significance value; $\mathrm{t}=$ Students's $\mathrm{t}$ - statistics value

\section{Interpretation}

The table(3.3) depicts perceived control component of ICT of school teachers on the basis of academic streams. It can be seen from the table that average score of perceived control component of ICT is similar for science and mathematics teachers and social science teachers. Independent sample ttest as performed to test its statistical significance. As it is depicted from the table that $p$ value is greater than assumed level of significance $(0.05)$. Therefore, there is no significant difference in perceived control component of ICT in school teachers on the basis of academic streams of Punjab.

Hence, null hypothesis H3 that there is no significant difference affective attitude towards ICT, perceived usefulness of ICT and perceived control component of ICT of school teachers is accepted on the basis of academic streams

\section{CONCLUSION}

Findings related to attitude towards ICT of school teachers

$>$ Secondary school teachers' affective attitude is significantly higher than primary school teachers.

$>$ Secondary school teachers significantly score higher than primary school teachers with respect to perceived usefulness of ICT.
Secondary school teachers significantly score higher than primary school teachers with respect to perceived control component of ICT.

$>$ Rural school teachers' affective attitude is significantly higher than urban school teachers.

$>$ Rural school teachers significantly score higher than urban school teachers with respect to perceived usefulness of ICT.

$>$ Rural school teachers significantly score higher than urban school teachers with respect to perceived control component of ICT.

$>$ Teachers of both streams (viz. Science/Mathematics \& Social sciences/ Languages) scored similar in affective attitude, perceived usefulness of ICT and perceived control component of ICT.

\section{REFERENCE}

[1] Adeya, N.C. (2002). ICTs and Poverty: A Literature Review.UNESCO. Available:http://www.idrc.ca/en/ev24718-201-1-DO_TOPIC.htm

[2] Albirini, A. 2004. 'Teachers' attitude toward information and communication technologies: the case of Syrian EFL teachers". Computers \& Education, vol. 47, no. 4 , pp. 373-398. 
[3] Jegede, P. O. (2006). A study of the predictors of teacher educators'behaviour towards ICT in furtherance Nigeria. Unpublished Doctoral Thesis: Obafemi Awolowo University, Nigeria.

[4] Cavas, B., Cavas, P., Karaoglan, B. \& Kisla, T. (2009). A study on science teachers' attitude toward information and communication technologies in education. The Turkish Online Journal of Educational Technology, 8 (2), Article-2. Retrieved from .=.0http://eric.ed.gov/?q=ATTITUDE+ \&ff1=dtyIn_ 2009\&id=ED505935
[5] International Encyclopedia of Education (1991). Frank N. Magill. Vol. 1, Fitz Roy Dearbor Publication England.

[6] Mehra, V. (2007). Teacher Attitude towards computer implications for Emerging Technology Implementation in Educational Institutions. Journal of Teacher Education and Research, 2(2), 1-13.

[7] UNESCO (2003). Developing and Using Indicators of ICT Use in Education. UNESCO-International Institute for Educational Planning. Retrieved from:http://portal.unesco.org/ci/en/ev.phpURL_ID $=12438 \& U R L \_D O=D O \_T O P I C$ $\&$ 